\title{
Sustainable Practices in research-integrated Education in HE: Towards an accepted Development Pedagogy
}

\section{Erika Corradini}

Centre for Higher Education Practice, University of Southampton, UK.

\begin{abstract}
Teaching ever so diverse cohorts of students requires educators to keep abreast of their professional learning and to acquire an open mindset towards their practice. With HE policy placing growing emphasis on teaching excellence, questions arise about how to measure teaching quality and about whether or not educators from across the board of disciplines are supported in doing so. How can lecturers devise evidence-based, valid and reliable measures for evaluating the quality of their teaching? The following piece conceptualises the relationship between education research and teaching practice through discussing their sustainable integration. The overarching aim of this study is to discuss the potential for action research to help educators to measure the quality of their teaching to improve students' outcomes and moving from this, to gauge how sustainable such practices can be in a fastpaced HE sector.
\end{abstract}

Keywords: higher education; professional development; sustainability; evaluation research; enhancement. 


\section{Introduction}

In UK Higher Education Institutions (HEIs) the idea of 'teaching excellence' and its interpretation have spurred a growing interest in teaching innovation and enhancement of the student learning experience. The pursuit of teaching excellence has inspired a gradual reconceptualization of the connection between education research and teaching practice. This concept of researching teaching practice has gradually upended the idea that research and teaching a separate spheres of action. Recent scholarship has invoked models underpinned by the ideal of the teacher as 'educational researcher' (MacFarlane and Hughes, 2009, pp.910) though the extent to which educators and lecturers in HE engage with this concept remains to be fully determined.

This study inquires about whether or not lecturers at one HE institution have a) changed their behaviours as a result of interrogating their practice and b) developed strategies to monitor, measure and improve the quality of teaching and the student learning experience. The overarching aim of this study is to offer a professional development perspective to the vexed question of whether a scholarly approach to teaching is sustainable as well as desirable, by analysing the complex iteration between education research and teaching practice.

This study is grounded in a longstanding and much researched approach to investigating teaching activity. Building on the principles of action research, (Van Manen, 1997; Walford, 1998; Norton, 2009 and Hoveid et al., 2019), this study develops teaching practitioners to engage with scholarly, evidence-based approaches to education and supports them to explore effective ways to transfer the outcomes into their teaching practice. The following discussion centres on the idea that teaching as research provides a valuable approach to measuring and improving the quality of students' outcomes and the learning experience. Herewith, I problematize the complex interaction of education research and teaching practice and I present practical suggestions for sustaining their integration in the long term.

\section{The study: the reflection-mediated method}

This study adopts a methodology based on the collection and analysis of qualitative evaluations and is underpinned by reflective practice as exemplified by Norton (2009, pp. 22-24) when arguing that reflective practice is inextricably linked to action research. Looking at engagement with education research through the practice of reflection has the potential to help us to determine whether or not teachers adopt scholarly approaches and what they make of these. Further, analysis of reflective texts provides a glimpse into the perceived outcomes of adopting scholarly practices and, in this way, it help us to gauge the impact this approach yields on learning development. Reflective practice is regarded as a means teachers utilise for making sense of how teaching works in their respective contexts. For this reason, I 
maintain that using reflective texts in this study will surface participants' behaviours in relation to the adoption of scholarly approaches to teaching practice.

\subsection{Data collection}

Evidence was collected from texts produced by a small group of 12 participants in an accredited educator development programme (Postgraduate Certificate in Academic Practice). Albeit this is a small sample of texts, the data collected allow for a preliminary insight into the behaviours of academic staff in making sense of their practice through the adoption of evidence-based methods. Data of this kind are difficult to obtain for the very reason which instigated this study, that the level of engagement with scholarly practices in university education is elusive and fragmented. However limited, this analysis aims to examine a pool of data with the aim to gather a preliminary understanding of the potential impact that utilising scholarly methods to improve teaching practice may have on teachers and students alike, hence the reason for focussing on a small data sample (Tracy, 2010). The production of reflective texts is essential for meeting the requirements of the assessment. Participants/educators are required to reflect on how their teaching has developed during the period of time they spent carrying out a learning enhancement project, a requirement of the programme. The reflection is guided by a brief and written against the learning outcomes (LOs henceforth) tested in the assessment.

Participants are required to write their reflective texts against a set of LOs in order to demonstrate that they achieved these in carrying out their projects. By reflecting on how they have a) applied pedagogical theory, b) underpinned their projects with the analysis of evaluation data and c) reviewed and changed their education design, participants are required to provide reasons for their professional learning.

\subsection{Data analysis}

Raw data were extracted from anonymised individual submissions and organised into three macro-groups, one for every LO. Data were then further disaggregated and examined by singling out sentences indicating the actions participants took to achieve the LO, especially active verbs indicating action (Biggs, 2011, pp. 120-121). All texts examined were analysed after completion of the programme. Participation in the study did not affect performance assessment and results in the educator programme.

Original reflections were broken up into sentences and parsed for active verbs to highlight the behaviours activated by the LOs: 23 sentences were extracted from the reflective texts (forming a corpus of ca. 9000 words) demonstrating active engagement with the intended outcomes with participants focussing on the action they took in progressing their learning enhancement project. A further step to the analysis was to see whether or not there is an indication that educators changed their behaviours as a result of researching their practice 
during the project. Although the sample examined is a small one, approximately $74 \%$ of the sentences extracted $(n=17 / 23)$ for analysis show a cause-effect relation evidencing that application of education research and/or the adoption of evidence-informed approaches had a positive impact on practice. A further $53 \%$ of this portion $(n=9 / 17$ sentences $)$ contain an indication that analysis of evaluation data justified a change in teaching and learning design.

Did educators translate research into practice? The statements reported above provide an impression of the participants' behaviours in using education research and evaluation data to understand their students' learning. The majority of the actions participants took had a positive impact on their teaching practice and are likely to have instigated change in teaching design which then entailed improvements in their teaching, in teacher-student relationships or in decision-making processes.

\section{Transferring research into practice: the implications}

Amongst the benefits of this study, four stand out which could potentially have an impact on the quality of teaching and learning. Data show that academics who engaged with education research a) developed an ability to transfer research outcomes to practice; b) used the data to make sense of their teaching; c) could replicate and implement the mechanisms across their practice and d) were able to support positive change and innovation with measurable benefits for their students.

\subsection{Levels of support model}

This study underpins the development of a model of support based on models developed by Evans (2017) and Paseka et al. (2019) in support of school teachers and emerging education researchers, respectively. In line with the studies mentioned above, the main problem about adopting scholarly practices in teaching is their sustainability. Similarly, a second area of concern is teachers' ability to make decisions and to take risks in teaching practice. Areas in which support could be provided to sustain the development of teacher-researchers are shown in the diagram below: 
Table 1. Areas of academic development

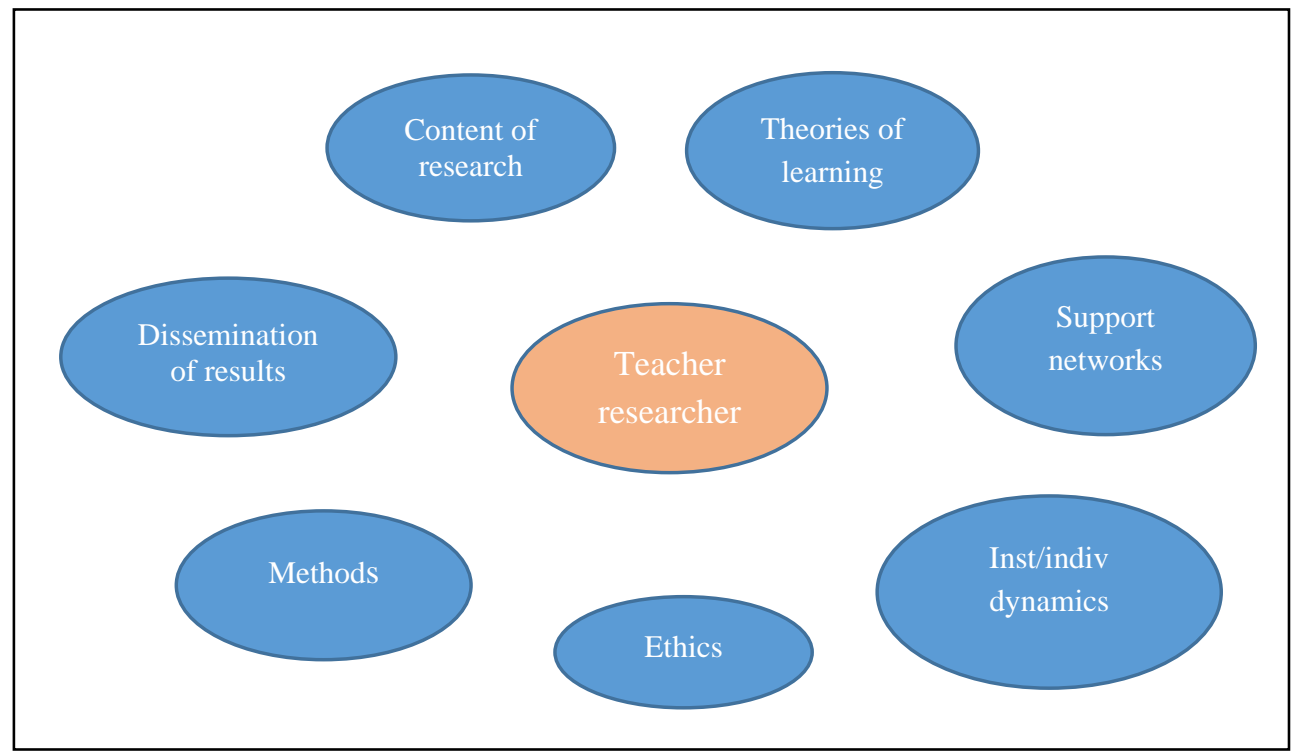

The model represents visually the context in which teacher-researchers operate. At the centre of a complex picture, the teacher-researcher is required to navigate an environment riddled with hurdles, often under the many pressures deriving from an ever growing diversification of the roles an academic is required to cover. Providing support in these areas in order to avoid disengagement seems therefore worth reflecting on. Creating support networks, protecting spaces for experimenting with new methods could potentially create a support structure for engaging educators with education research, providing them with the space where they can evaluate the quality of their teaching, innovate and develop their practice. 


\section{References}

Biggs and Tang (2011), Teaching for quality learning at university, Palgrave.

Caldwell, M., Simkin, T., Level models of continuing professional development evaluation: a grounded review and critique, Professional Development in Education, 37:1, 143-157.

D'Andrea, V., and Gosling, D. (2001). Joining the dots: Reconceptualizing educational development. Active Learning in Higher Education, 2(1), 64-80.

Evans, C. (2017) 'Early career teachers research literacy: what does it look like and what elements support its development in practice?', Research Papers in Education, 32:4, 540551.

Guskey, T., 2000. Evaluating professional development. Thousand Oaks, CA: Corwin Press.

Macfarlane, B. and Hughes, G. 'Turning teachers into academics? The role of educational development in fostering synergy between teaching and research', Innovations in Education and Teaching International, 46:1, 5-14.

McKinney, K. (2007) Enhancing learning through the scholarship of teaching and learning. The challenges and joys of juggling, Anker Publishing.

McLean N. and Price L. (2017) 'Identity formation among novice academic teachers-a longitudinal study', Studies in Higher Education.

Norton, L. S. (2009) Action Research in Teaching and Learning. Routledge.

Paseka, S., Marques da Silva, L. Ciolan and M. Honerod Hoveid, (2019) Educational Research-A Space of Risk and Uncertainty, in A. Paseka, S. Marques da Silva et al. (eds) Doing Educational Research. Overcoming Challenges in Practice (EERA).

Robertson, J. and Bond, C. H. (2001) 'Experiences of the Relation between Teaching and Research: What do academics value?' Higher Education research and Development, 20:1, 5-19.

Ruutman T. and Saar M. (2017) Scholarly Teaching and Scholarship of Teaching and Learning in Teaching Engineering, Global Engineering Education Conference, (EDUCON), 213-218.

Tracy (2010), Qualitative Quality: Eight “Big-Tent" Criteria for Excellent Qualitative Research, SAGE Publishing.

Webster-Wright, A., 2009. Reframing professional development through understanding authentic professional learning. Review of Educational Research, 79 (2), 702-739. 